\title{
Gene expression in the lignin biosynthesis pathway during soybean seed development
}

\author{
A. Baldoni, E.V.R. Von Pinho, J.S. Fernandes, V.M. Abreu and \\ M.L.M. Carvalho \\ Laboratório Central de Sementes, Departamento de Agricultura, \\ Universidade Federal de Lavras, Lavras, MG, Brasil \\ Corresponding author: A. Baldoni \\ E-mail: alexanabaldoni@yahoo.com.br
}

Genet. Mol. Res. 12 (3): 2618-2624 (2013)

Received May 5, 2012

Accepted November 10, 2012

Published February 28, 2013

DOI http://dx.doi.org/10.4238/2013.February.28.2

\begin{abstract}
The study of gene expression in plants is fundamental, and understanding the molecular mechanisms involved in important biological processes, such as biochemical pathways or signaling that are used or manipulated in improvement programs, are key for the production of highquality soybean seeds. Reports related to gene expression of lignin in seeds are scarce in the literature. We studied the expression of the phenylalanine ammonia-lyase (PAL), cinnamate 4-hydroxylase, 4-hydroxycinnamate 3-hydroxylase, and cinnamyl alcohol dehydrogenase genes involved in lignin biosynthesis during the development of soybean (Glycine max L. Merrill) seeds. As the endogenous control, the eukaryotic elongation factor 1-beta gene was used in two biological replicates performed in triplicate. Relative quantitative expression of these genes during the R4, R5, R6, and R7 development stages was analyzed. Real-time polymerase chain reaction was used for the gene expression study. The analyses were carried out in an ABI PRISM 7500 thermocycler using the comparative $\mathrm{Ct}$ method and SYBR Green to detect amplification. The seed samples at the R4 stage were chosen as calibrators. Increased expression of the cinnamate-4-hydroxylase and $P A L$ genes occurred in soybean seeds at the R5 and R6 development stages. The cinnamyl alcohol dehydrogenase gene was expressed during the
\end{abstract}


final development phases of soybean seeds. In low-lignin soybean cultivars, the higher expression of the $P A L$ gene occurs at development stages R6 and R7. Activation of the genes involved in the lignin biosynthesis pathway occurs at the beginning of soybean seed development.

Key words: Gene expression; Quantitative real-time PCR; Lignin; Seeds; Soybean

\section{INTRODUCTION}

Soybean is considered one of the most important and most widely grown crops in the world. It contains significant quantities of proteins and a considerable percentage of oil, which has made it highly important in the industrial sector for food products, cosmetics, and more recently, biofuels.

To meet the growing demands of the industrial sector, soybean stands with high yields must be established through the use of seeds with excellent physiological qualities. As such, genetic variability among soybean genotypes for characteristic physiological seed qualities has been used in genetic breeding programs. Molecular studies involving gene expression in soybeans related to drought tolerance have already been carried out to improve the tolerance of soybean cultivars to environmental stress (Stolf-Moreira et al., 2010; Polizel et al., 2011). However, studies of the lignin biosynthesis pathway in soybean seeds remain scarce in the literature.

Among factors that affect seed quality, seed coat characteristics, mainly those related to lignin accumulation, have been examined (Krzyzanowski, 1998; Krzyzanowski et al., 2008). Lignin provides rigidity and hydrophobic properties, favoring resistance to mechanical damage, water transport, and defense against pathogen attacks (Boerjan et al., 2003; Boudet et al., 2003).

Lignin synthesis involves various enzymes, knowledge of which is important in studies in which soybean seed quality is related to lignin content. The complexity of the lignin biosynthesis pathway is attributed to various multifunctional enzymes, and these enzymes also correspond to different gene families (Xu et al., 2009). Molecular studies have proven to be fundamental for better understanding their complexity. Recently, elucidation of the function and evolution of genes involved in lignin biosynthesis have been required for research seeking to improve raw materials for bioenergy (Xu et al., 2009). Within this context, the purpose of our study was to examine the expression of phenylalanine ammonia-lyase $(P A L)$, cinnamate 4-hydroxylase $(C 4 H)$, 4-hydroxycinnamate 3-hydroxylase $(C 3 H)$, and cinnamyl alcohol dehydrogenase $(C A D)$ genes involved in the lignin metabolic pathway during the development of soybean seeds with various lignin contents.

\section{MATERIAL AND METHODS}

\section{Plant material}

Analysis of gene expression was performed with a real-time quantitative polymerase chain reaction technique using soybean seeds with high (BRS Silvânia RR and Doko) and low (BRS Celeste and BRS 133) lignin content. The experiment was performed in the field with the harvest of the seeds during the R4, R5, R6, and R7 development stages according to a procedure published by Fher and Caviness (1977). The seeds were placed immediately in liquid nitrogen and stored at $-80^{\circ} \mathrm{C}$ until RNA extraction. 


\section{Total RNA extraction and cDNA synthesis}

All materials used were treated in advance with $0.1 \%$ diethylpyrocarbonate-treated water to inhibit RNase activity. Total RNA was extracted in two biological replicates for each sample using the PureLink Plant RNA reagent (Invitrogen, Carlsbad, CA, USA) according to manufacturer recommendations and was later treated with DNase (Ambion, Austin, TX, USA) to eliminate possible DNA contamination. To obtain cDNA, we used a High-Capacity cDNA Reverse Transcription kit (Applied Biosystems, Foster City, CA, USA).

\section{Primer design}

Gene sequences were obtained with a National Center for Biotechnology Information similarity search. Primers were designed using Primer Express 3 (Applied Biosystems) and are presented in Table 1. The genes $\beta$-actin, cyclophilin $C Y P 2$, and $E L F 1 B$ were selected as endogenous controls because they have constitutive expression, and the $E L F 1 B$ gene was chosen for normalization because its level of expression remains constant throughout the stages of seed development.

\begin{tabular}{ll}
\multicolumn{2}{c}{ Table 1. Primer sequences of genes utilized in real-time quantitative PCR. } \\
\hline Gene & Primer sequences \\
\hline$\beta$ actin $\mathrm{F}$ & 5'-TCCAAGGGGACCTAACGGAGA-3' \\
$\beta$ actin $\mathrm{R}$ & 5'-TGGGTCAAGAGCTGGATGGTG-3' \\
$C Y P 2 \mathrm{~F}$ & 5'-CGGGACCAGTGTGCTTCTTCA-3' \\
$C Y P 2 \mathrm{R}$ & 5'-CCCCTCCACTACAAAGGCTCG-3' \\
$E L F B \mathrm{~F}$ & 5'-GTTGAAAAGCCAGGGGACA-3' \\
$E L F B \mathrm{R}$ & 5'-TCTTACCCCTTGAGCGTGG-3' \\
$C 3 H \mathrm{~F}$ & 5'-TCCTGACTATTATTCCGCATCAC-3' \\
$C 3 H \mathrm{R}$ & 5'-TTATCACACATGCGCTTGAATTT-3' \\
$C A D \mathrm{~F}$ & 5'-TGTTGCTGCAGTTGCGTACA-3' \\
$C A D \mathrm{R}$ & 5'-CGGAAACCAAGTCTCATCAACTA-3' \\
$P A L \mathrm{~F}$ & 5'-AACAACGGCACTGACAGTTACG-3' \\
$P A L \mathrm{R}$ & 5'-GAGCACCACCCTGTTGGTT-3' \\
$C 4 H \mathrm{~F}$ & 5'-CGCACAAGGCGTAGAATTTG-3' \\
C4H R & 5'-CCATTCCCCGTGAAGATATCA-3' \\
\hline
\end{tabular}

$\mathrm{F}=$ forward $\mathrm{R}=$ reverse.

\section{Real-time quantitative PCR}

Reactions were prepared in triplicate for each of the two biological replicates and performed in an ABI PRISM 7500 Real-Time PCR thermocycler (Applied Biosystems) using SYBR Green PCR Master Mix (Applied Biosystems). The relative quantitative expression was determined using method $2^{-\Delta \Delta C t}$, considering seeds in the R4 stage as calibrators.

The reaction conditions were as follows: $50^{\circ} \mathrm{C}$ for $2 \mathrm{~min} ; 95^{\circ} \mathrm{C}$ for $10 \mathrm{~min} ; 45$ cycles of $95^{\circ} \mathrm{C}$ for $2 \mathrm{~min}, 62^{\circ} \mathrm{C}$ for $30 \mathrm{~s}$, and $72^{\circ} \mathrm{C}$ for $30 \mathrm{~s}$. An amplification efficiency curve was determined for each gene using $5 \mathrm{cDNA}$ dilutions $\left(10,10^{-1}, 10^{-2}, 10^{-3}\right.$, and $\left.10^{-4}\right)$. After standardizations, the amplification reactions were conducted in a final reaction volume of $20 \mu \mathrm{L}$ containing $10 \mu \mathrm{L}$ SYBR Green PCR Master Mix (Applied Biosystems), $2 \mu \mathrm{L} 80$ ng cDNA, 0.4 $\mu \mathrm{L}$ each of forward and reverse primers, and $7.2 \mu \mathrm{L}$ ultrapure autoclaved water.

After amplification using real-time PCR, each amplification product was analyzed 
with a dissociation curve certifying that for each gene and treatment, the amplified product did not show nonspecific bands or primer dimer formation. Data analysis was performed using the 7500 Software SDS program (version 2.0.1; Applied Biosystems).

\section{RESULTS AND DISCUSSION}

We observed greater expression of the $C 4 H$ gene in seeds with both high and low lignin content in the R5 stage of development. Notably, however, in seeds of the high lignin content cultivars Doko and BRS Silvânia RR (Figures 1 and 2), the levels of $C 4 H$ expression were greater than those observed in the seeds of the cultivars BRS Celeste and BRS 133 (Figures 3 and 4), which are classified as having low lignin content.

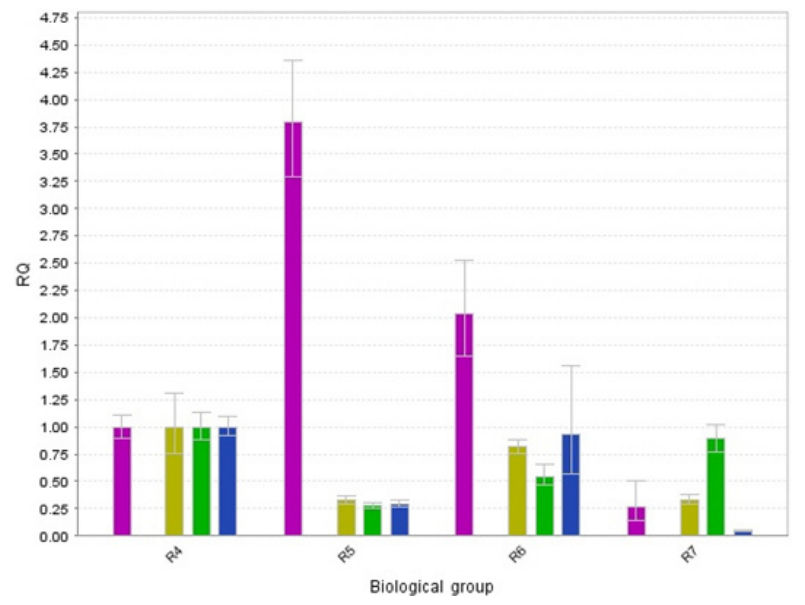

Figure 1. Profile of relative quantitative (RQ) expression of the genes $C 3 H, C 4 H, C A D$, and $P A L$ during the stages of development of soybean seeds. Doko cultivar (high lignin content).



Figure 2. Profile of relative quantitative (RQ) expression of the genes $C 3 H, C 4 H, C A D$, and $P A L$ during the stages of development of soybean seeds. BRS Silvânia RR cultivar (high lignin content). 


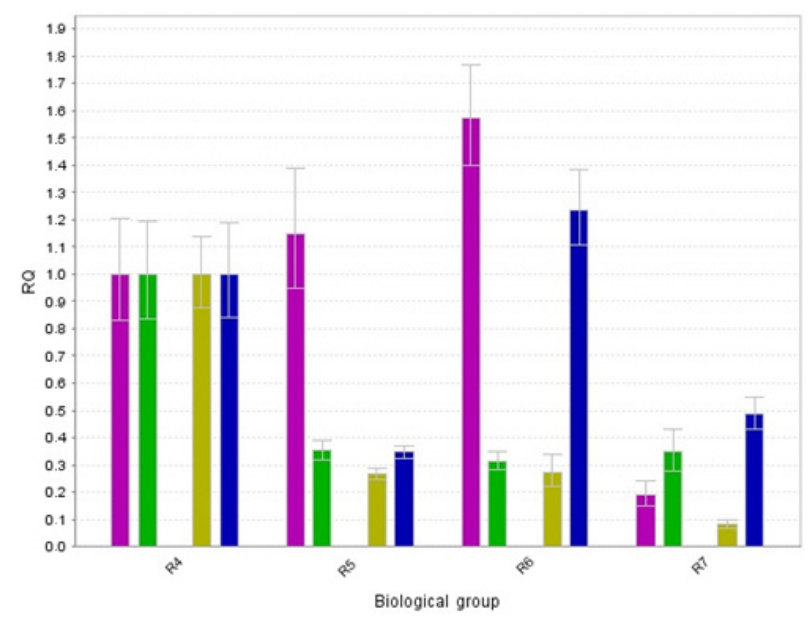

Figure 3. Profile of relative quantitative (RQ) expression of the genes $C 3 H, C 4 H, C A D$, and $P A L$ during the stages of development of soybean seeds. BRS Celeste cultivar (low lignin content).

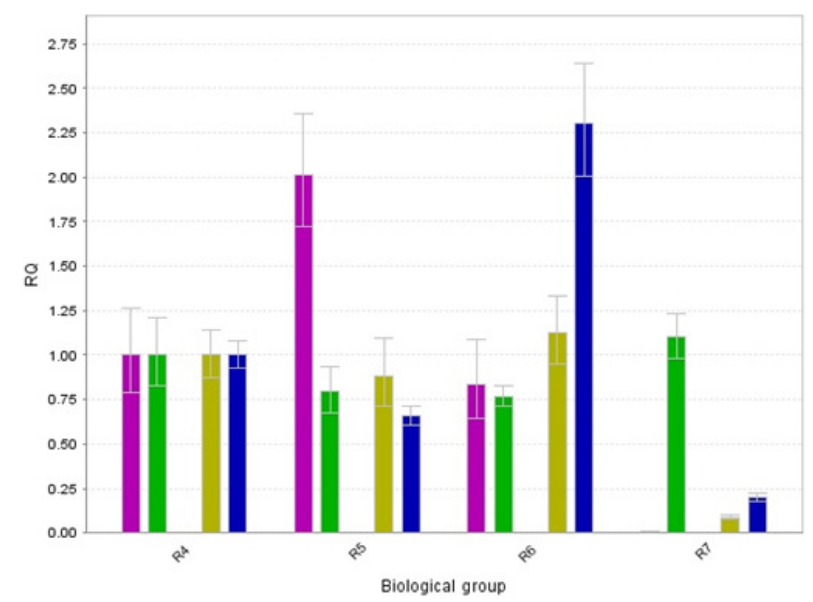

Figure 4. Profile of relative quantitative (RQ) expression of the genes $C 3 H, C 4 H, C A D$, and $P A L$ during the stages of development of soybean seeds. BRS 133 cultivar (low lignin content).

In seeds from the cultivars Doko and BRS Silvânia RR (see Figures 1 and 2) in the R6 stage, $\mathrm{C} 4 \mathrm{H}$ expression predominated among the others studied. Nevertheless, in numerical terms, expression in seeds of the Doko cultivar was greater than that in seeds of the BRS Silvânia RR cultivar.

C4H expression also occurred in seeds of the BRS133 cultivar (see Figure 4) in the R6 stage. However, $P A L$ expression was greater in seeds in this stage of development. A comparison of this value to $P A L$ expression in the other cultivars and in the R6 stage of development revealed the greatest expression in seeds in the BRS 133 cultivar.

In seeds in the R6 and R7 stages, greater expression of the $P A L$ gene was observed in cultivars with low lignin content (see Figures 3 and 4) than in cultivars with high lignin con- 
tent. According to Zhao et al. (2005), expression of the $P A L$ gene is highly influenced by the environment because it is related to plant protection. This relationship suggests that the seeds of these cultivars may have undergone biotic or abiotic stress during the production process, increasing the expression of this gene.

Greater expression of $C 3 H$ was observed in seeds of the BRS 133 cultivar (see Figure 4) in the R5 and R6 stages of development. In the other cultivars, expression was low in all stages of development. $C 3 H$ hydroxylates p-coumaric acid after $C 4 H$ (Dixon et al., 2001). According to Darley et al. (2001), both compounds participate in the initial stages in the formation process of lignin precursors.

In all the cultivars studied, greater expression of the $C A D$ gene was observed in seeds in the R7 stage of development than in the R5 and R6 stages. CAD is involved in the last stage of biosynthesis of the monolignols, and because it has high specificity, it is considered a marker of the lignification process (Kiedrowski et al., 1992).

We presume that the expression of this gene is important in the final stages of seed development, near the point of physiological maturity of the seeds. In general, greater expression of the $C 4 H$ and $P A L$ genes was observed in seeds in the R5 and R6 stages of development. These genes are involved in the initial stages of the lignin biosynthesis process. Both $P A L$ and $\mathrm{C} 4 \mathrm{H}$ are active in the formation of lignin precursors (Raes et al., 2003).

\section{CONCLUSIONS}

Greater expression of the $C 4 H$ and $P A L$ genes occurred in soybean seeds in the R5 and R6 stages of development. The $C A D$ gene is expressed in the final phases of development of soybean seeds. In the seeds of soybean cultivars with low lignin content, greater expression of the PAL gene occurred in the R6 and R7 stages of development. Activation of the genes involved in the lignin biosynthesis pathway occurs at the beginning of soybean seed development.

\section{ACKNOWLEDGMENTS}

Research supported by Conselho Nacional de Desenvolvimento Científico e Tecnológico. We thank Universidade Federal de Lavras for laboratory facilities.

\section{REFERENCES}

Boerjan W, Ralph J and Baucher M (2003). Lignin biosynthesis. Annu. Rev. Plant Biol. 54: 519-546.

Boudet AM, Kajita S, Grima-Pettenati J and Goffner D (2003). Lignins and lignocellulosics: a better control of synthesis for new and improved uses. Trends Plant Sci. 8: 576-581.

Darley CP, Forrester AM and McQueen-Mason SJ (2001). The molecular basis of plant cell wall extension. Plant Mol. Biol. 47: 179-195.

Dixon RA, Chen F, Guo D and Parvathi K (2001). The biosynthesis of monolignols: a "metabolic grid", or independent pathways to guaiacyl and syringyl units? Phytochemistry 57: 1069-1084.

Fehr WR and Caviness CE (1977). Stage of Soybean Development. Iowa State University, Ames.

Kiedrowski S, Kawalleck P, Hahlbrock K, Somssich IE, et al. (1992). Rapid activation of a novel plant defense gene is strictly dependent on the Arabidopsis RPM1 disease resistance locus. EMBO J. 11: 4677-4684.

Krzyzanowski FC (1998). Relationship between seed technology research and federal plant breeding programs. Sci. Agric. 55: 83-97.

Krzyzanowski FC, Franca Neto JB, Mandarino JMG and Kaster M (2008). Evaluation of lignin content of soybean seed coat stored in a controlled environment. Rev. Bras. Sementes 30: 220-223. 
Polizel AM, Medri ME, Nakashima K, Yamanaka N, et al. (2011). Molecular, anatomical and physiological properties of a genetically modified soybean line transformed with rd29A:AtDREB1A for the improvement of drought tolerance. Genet. Mol. Res. 10: 3641-3656.

Raes J, Rohde A, Christensen JH, Van de Peer Y, et al. (2003). Genome-wide characterization of the lignification toolbox in Arabidopsis. Plant Physiol. 133: 1051-1071.

Stolf-Moreira R, Medri ME, Neumaier N, Lemos NG, et al. (2010). Soybean physiology and gene expression during drought. Genet. Mol. Res. 9: 1946-1956.

Xu Z, Zhang D, Hu J, Zhou X, et al. (2009). Comparative genome analysis of lignin biosynthesis gene families across the plant kingdom. BMC Bioinformatics 10 (Suppl 11): S3.

Zhao J, Davis LC and Verpoorte R (2005). Elicitor signal transduction leading to production of plant secondary metabolites. Biotechnol. Adv. 23: 283-333. 